\title{
Playing with clay and the uncertainty of agency. A Material Engagement Theory perspective
}

\author{
Paul Louis March ${ }^{1}$
}

Published online: 7 December 2017

(C) The Author(s) 2017. This article is an open access publication

\begin{abstract}
I describe how close attention to the process of sculpting clay from the perspective of Material Engagement Theory can create a detailed description of a mutable sense of agency and of self. First, I show that sculpting is associated with a loss of sense of agency and self. Second, that to sense agency as a systemic phenomenon (rather than a personal attribute) creates anxiety. Third, that meaning in an art encounter develops in association with an anterospective viewpoint. Fourth, that within the logic of the extended mind, emergent meaning becomes openly available for further exploration (meta-cognition). Fifth, that artistic creativity is not an opaque process. It proceeds in a similar manner to other forms of human, sense-making activities. Finally, that playing seriously with clay can be used in an investigative manner - as a tool for material conceptualisation.
\end{abstract}

Keywords Material engagement · Agency · Enactive signification · Art · Extended cognition

\section{Introduction}

In this paper, I describe how close attention to the process of sculpting clay from the perspective of Material Engagement Theory (MET) can create a detailed description of a mutable sense of agency and sense of self. I do not claim that a single, subjective account can be generalised to say anything directly about the nature of agency per se. My aim is rather to describe my sense of self whilst sculpting in order to explore and test some key concepts from MET.

In part, this is an attempt to resolve two contradictory personal experiences. As a former clinical psychologist, trained during the post-behavioural, cognitive revolution

Paul Louis March

paul.march@keble.ox.ac.uk

1 Keble College, University of Oxford, Oxford OX1 3PG, UK 
and specialising in neuro-rehabilitation, I understood perception to involve the construction of internal representations of the world (e.g. Palmer 1999 for a full account of this view). I assumed that creativity was explained by the mapping and manipulation of internal conceptual spaces (e.g. Boden 1994, 2004). And I held agency to be the triumph of mind over matter. "Through cognitive self-regulation, humans can create visualised futures that act on the present; construct, evaluate, and modify alternative courses of action to secure valued outcomes; and override environmental influences." (Bandura 2006 p. 164). Now a sculptor who works with clay I find these information processing models of the mind incompatible with the process of making. Sculptural forms seem to arise directly from the interaction between my body (eyes, arms and hands) and the clay. It feels like the clay and I create something together.

I will begin by describing how the information processing account determines our view of agency and creativity. I will then consider an alternative formulation using MET (Malafouris 2013). A key aspect of MET is the proposition that sense and form are recursively co-dependent, creating an experience that is unmediated by languagewhat Malafouris (2013) calls "enactive signification". I will explore the importance of enactive signification for art-making using three case studies. By doing so I wish to show first, that on occasions of intense engagement with clay, the boundaries of what I consider to be myself become uncertain or permeable. There no longer appears to be a sharp division between what is me and what is not me. From a MET perspective, we could say that the mind extends to include the clay in its act of plastic deformation. Malafouris refers to this as "Creative Thinging" (2014). But this growing awareness of the mind's plasticity undermines the notion of a stable self. Second, that meaning in an art encounter emerges in association with an anterospective viewpoint. Third, if the brain and the mind do not inhabit the same space; if the mind extends into the world of material things, then the activities of the mind become visible to us. In short, we can see ourselves thinking. (Malafouris 2007). Malafouris calls this "metacognition (thinking about thinking)" (2013, p.77) Fourth, by drawing a parallel between a MET-informed analysis of sculpting and Latour's (1999) analysis of scientific advancement I show that making art is not a special case of creativity but proceeds in similar ways to other forms of human, sense-making activities. And finally, by looking carefully at the way sculptures come into being, I want to show that sculpting can be used in an investigative manner - as a tool for material conceptualisation.

\section{The hylomorphic model}

From Aristotle, we inherit the notion that a thing consists of the matter (hyle) of which it is made and the form (morphe) that matter takes. If form and matter are separated in this way, the creation of new forms requires an active agent to conceive of an idea and then to impose it on passive matter. This view of agency is succinctly summarised by Barandiaran et al. (2009, p. 370).

The first condition for the appearance of agency is the presence of a system capable of defining its own identity as an individual and thus distinguishing itself from its surroundings; in doing so, it defines an environment in which it carries out its actions.

To illustrate the hylomorphic model, Ingold (2010, pp. 22-23) describes how the role of the architect has changed since medieval times from one of master builder 
working in concert with materials, to becoming an expert in the manipulation of precise but abstract geometrical forms. The true creative locus becomes located in the mind of the conceiver. The doer takes instruction from the conceiver rather than guidance from the material. This view - consistent with Boden - finds its apotheosis in the development of conceptual art. Sol Le Witt, one of the movement's pioneers, described it in the following terms

"In conceptual art the idea or concept is the most important aspect of the work. When an artist uses a conceptual form of art, it means that all of the planning and decisions are made beforehand and the execution is a perfunctory affair." (Le Witt 1967, p.79)

But the neat split between important idea and perfunctory execution is blurred if we explore how the planning and decision-making actually comes about. When the contemporary conceptual artist, Damien Hirst recounts the origins of some of his most famous works they turn out to be, not abstract reflections, mechanically rendered into material form, but embedded in the physicality of his artistic practice. Here, for example, he describes the inception of his series of butterfly paintings:

"I was priming a canvas and flies were landing in the paint. I remember thinking - again like an imaginary painter who'd be trying to paint monochromes and insects kept screwing it up and then they became the work. And I thought wouldn't it be brilliant if they were butterflies. So, the by-product of something horrible happening - like an insect in the paint — became a great thing." (Hirst 2012, 15-15.30 mins)

If we go beyond conceptual art into the milieu of art in general, the hylomorphic model appears even more unlikely. Here is how Francis Bacon attributes agency and creativity.

"I foresee it in my mind, I foresee it, and yet I hardly ever carry it out as I foresee it. It transforms itself by the actual paint... I don't know very often what the paint will do and it does many things much better than I could make it do." (Sylvester 1975, p. 16).

Returning to Barandiaran and colleagues, they concede that the neat agentenvironment split that they propose is challenged by questions of co-dependence between the two.

"How does niche construction (for example) relate to agency? Should those environmental features that recurrently depend on the agent be considered as part of the agent? What is the status of tools as mediators between agents and environments?" (2009, p. 381.)

One solution to the dilemma is to take a more reciprocal view of agency and extend and distribute it throughout the environment. This is essentially the position taken by Gell and Latour. In brief, Gell (1998) proposed that we exhibit primary agency and the materials we use derive a secondary agency from our interactions with them. Gell suggests that the act of making something breathes agency into it. This, in turn, influences the development, culture and lives of humans.

For Latour (e.g. 1996) the world contains the constant potential for the formation of networks of action between humans, artefacts, things, ideas and cultural constructions. Agency emerges only when these elements come together to form actual networks and becomes distributed symmetrically across those networks. 
Ingold has questioned the value of agency as a concept, $(2010,2013)$ pointing out that the approaches of Gell and Latour perpetuate a linear model of causality in which, irrespective of the nature of the agent, action is divided into cause and effect. I am not sure the criticism is warranted in the case of Latour who sees agency as an emergent property of a network in formation rather than something to be partitioned. Both Latour and Ingold wish to reunify the act of creation first by changing "form" and "matter" from nouns into verbs - "forming" and "mattering"; and second, by suggesting that each engenders the other. This dynamic ontological position in which agency does not exist independently of action is similar to that proposed by MET.

\section{Material Engagement Theory}

Developed within an archaeological context by radically re-framing the ontological status of artefacts, Malafouris (2013) describes how things and thinking are related. Instead of using a stone axe, for example, as a clue to the structure of the mind of Palaeolithic man, Malafouris suggests that we view the axe as an active and indispensable part of the cognitive architecture of the maker. And rather than seeing creation as the imposition of a preconceived internal image onto a lump of flint (as with hylomorphism), he proposes that the materiality of the flint not only actively shapes a specific tool but is ontogenetically and phylogenetically inseparable from the mind and body that made it. (Malafouris 2013, 2015).

As with Ingold and Latour, the fundamental shift here is away from perceiving artefacts in terms of forms and shapes, and towards experiencing them as a series of gestures and actions - what Malafouris calls, "the hylonoetic field of human becoming" (2014 p. 142). Not only does this mean that we humans literally have a hand in our own ontological development but this development is visible to us in the interactions between our hands and the materials in front of us. By taking notice of the unfolding action, we take a meta-position with regard to our experience of the world. With regard to thinking, Malafouris (2013, p. 77) calls this "metacognition (thinking about thinking)" Taking a meta-position can apply equally to feelings. Malafouris (2014) notes that the interactions between potters, the clay and the wheel are expressed as a "feeling of and for clay". Here the word feeling means something different from its normal use in day-to-day language. A feeling is typically understood to be a consequence of something, e.g. "I feel sad and upset because you rejected me." But in the context of engaging with clay, a feeling is an expression of the dynamic co-created energy of the ongoing activity of modelling. The work of sculpting proceeds with a "feeling of and for clay" which emerges in the activity between my hands. The feelings are simultaneously both conceived and experienced by this manufacturing system. In addition, they are available for examination. I want to call this "meta-emotion" (having thoughts and feelings about feelings).

\section{Enactive signification}

From the perspective of understanding art-making, perhaps the most important aspect of MET is its reformulation of the relationship between things and meaning. 
Malafouris $(2007,2013)$ uses the cave paintings of Chauvet to question the notion of representation and to demonstrate that there is nothing about a painting of a rhinoceros that should lead us to assume that it is standing in for a real rhino in the way the word "rhinoceros" does.

"To say that a painting from Chauvet "resembles" or "looks like" a rhinoceros does not necessarily imply that the painting also represents a rhinoceros in a conceptmediated manner...I am not questioning that the picture can be taken as evidence of seeing a rhino; I am, rather, questioning that it can be taken as evidence of a consciousness that represents or stands for something to be found beyond the depicted thing itself." (p. 199).

Malafouris (2013, p. 90) refers to the translation of material expression into language as "the fallacy of the linguistic sign". In art appreciation, it is this automatic, unnoticed transformation that prompts questions such as; "What does this sculpture mean?" or "What are you trying to say?". Such questions reveal the agency of representation to be linear, unidirectional and retrospective-brought about by the division of the world into stimulus and response. Malafouris' contention is that material signs are not symbols that represent or stand in for a concept. Rather, the concept is conceived at the moment of materialisation. The signifier and the signified arise simultaneously. Malafouris (2013, p.99) calls this "enactive signification". With this view, art is liberated from its representative role. It can no longer be held up to the world as a mirror. Art becomes simultaneously part of the world and an expression of the world.

\section{Playing with clay}

Over the last 3 years two tonnes of clay have passed through my hands, taking on various shapes and sizes before being heated to around $1200{ }^{\circ} \mathrm{C}$. I mention the weight of the clay and the temperature of the kiln to emphasise that what I will go onto say about experience is related to physical and material transformations. The physicality of sculptural experience can be felt by comparing two different clays: stoneware and porcelain. Metaphorically speaking, stoneware is dynamic, generous and forgiving - confident in its plastic potential. Porcelain is intransigent and full of inertia. With porcelain, the act of creation and the outcome of the engagement with my hands take place within boundaries set by the clay's limited elasticity and excessive friability. Sculpting with porcelain is a tense negotiation.

Before continuing I want to describe why I think "playing" is a good word in this context. Memories of playing as a child and my experiences of making clay sculptures bear certain strong similarities. Playing, like making sculptures, is a way of exploring the world in which, within the constraints of the game, the signification of things is enacted in unusual and metaphorical ways. Like creative thinging and unlike traditional theatre, play does not reach for a resolution. Like creative thinging, time and space are brought under the command of the game and expand or contract according to the requirements of each playful moment. Like sculpting, I can accept the incompleteness of play even as I am lost in the act of make-believing. 
I will now present three examples of playing with stoneware in order to explore how sculpting clay also traces its own actions.

\section{The Substantia Inomminata series}

Here are three possible ways of describing how this series of sculptures (2013) came into being.

(i) For 9 months, I took lumps of clay, pushed them together, pulled bits off, squashed them and coaxed them into changing their form.

(ii) For 9 months, lumps of clay pushed against my hands and each other, coalescing and fragmenting, taking and changing form.

(iii) For 9 months, lumps of clay and my hands danced together in response to shapes left in the clay by previous dances.

There are many more versions of what took place during those 9 months. But simply comparing these three demonstrates how description defines agency. Each description is validated by changing either the perspective or the starting point of the narrative. Let us call the first description the normal (hylomorphic) one: human agency as it is mythologised. The second, whilst not explicit, is difficult to read without concluding that the author was an animist. The third has the metaphorical ring of an artist's reflections. It is not as troubling as the second because the existence of metaphor allows us to believe that the artist thinks that s/he remains the agent.

Giving an account of what it is like to play with clay is not going to be easy. Even "playing with clay" as opposed to "reacting to form" defines both the doer and the done-to. Part of the problem, as Ingold notes (2014a), is linguistic. We are obliged by language to divide the world into active and passive elements. Ingold refers us to the work of linguist Benveniste:

"....in the history of the Indo-European languages the active/passive opposition emerged through a decomposition of what ancient Greek grammarians called the 'middle voice'. It was this decomposition that put agency, as it were, out in front, separating the doer from the deed. In the middle voice, by contrast, the doer remains inside the process of his doing; "he achieves something", writes Benveniste, "which is being achieved in him" (Benveniste 1971, p. 149).

In the absence of a middle voice I will sometimes make recourse to metaphor. In order to speak without prejudice, it is sometimes necessary to ascribe life-like qualities to inanimate clay.

The Substantia Inomminata series (Image 1) was an attempt to create highly structured yet perceptually indeterminate forms in order to explore the extent to which structure and indeterminacy can co-exist. The aim was to arrive at a tight, coherent sculpture that gave the impression that there was something to recognise without it ever settling into an acceptable thing in the eye of the beholder. We might call this overarching aim a "prior intention". But as Malafouris argues (2008a, b, 2011, 2013), if we take context into account, in this case a series of antecedent projects, 


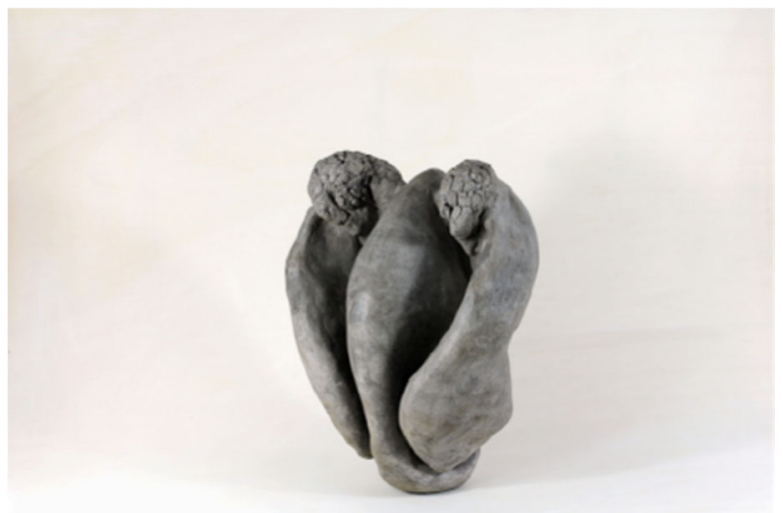

Image 1 Substantia Inomminata IV (2014) $0.35 \times 0.35 \times 0.25 \mathrm{~m}$. (For the whole Substantia Inomminata series, see www.paul-march.com/section/403550-substantia-innominata-series.html)

prior intention becomes embedded in prior action-what Gallagher and Miyahara (2012) call "enactive intentionality".

The simultaneous development of structure and indeterminacy requires a particular sort of awareness, which I will discuss later in relation to the poet, Keats's notion of 'Negative Capability'. For the moment, it is enough to say that this awareness involves two, related tasks. The first is the usual one of sculpting during which a lump of clay and I engage in creative thinging. The second involved paying attention to the emergence of agency and the intentional origins of sculpting. Defined thus, sculpting becomes an act of participant observation "....knowledge....consists not in propositions about the world but in the skills of perception and capacities of judgment that develop in the course of direct, practical, and sensuous engagements with our surroundings. "(Ingold 2014b, p. 387). Milner (1950) calls this process of realisation though doing "contemplative action. The act of monitoring makes explicit a metacognitive/ meta-emotive position that is implicitly present in exploratory art-making. As Malafouris \& Koukouti, put it, "The feeling of and for clay designates, on the one hand, the experience of absorption in and submission to the material, and on the other the parallel active exploration of an ongoing improvisation with the material." (Malafouris and Koukouti 2017, p. 297).

The requirement to pay attention to the emergence of agency had a profound effect on me. The emerging Substantia Inomminata sculptures challenged the ubiquitous separation of the world into nature and culture. The strange, developing shapes paradoxically suggested that they could also have been thrown up by a process of ossification, fossilisation or non-human, animal activity. The act of monitoring blurred the distinction between my repetitive movements and so-called natural phenomena such as, bees making nests or plants growing leaves. Others have had similar Damascene experiences. For Bennett (2010 pp. 4-6) a chance encounter with some debris in the street lead her to experience the vibrancy of matter. Renfrew (2003) describes how he positively reappraised a Richard Long installation (Chalk Line, 1979) when he remembered a particular archaeological dig. His re-evaluation recursively convinced him to see his own, experiential reactions during excavations as an integral part of archaeological exploration. For these authors, as for me, a material encounter created a new ontological experience. 
Hogan and Pink (2010) and Renfrew (2003) suggest that art does not resolve anything. It replaces certainty with doubt. It was certainly the case here. Contemplative action called into question, not only the nature-culture distinction, it was also dismantling my sense of self, replacing it by the notion that I was a typical brain and body, following the laws of the universe like any other system - organised by the universe like everything else. In this state, language becomes less important — unnecessary or even unhelpful. I am reminded of Humphrey's (1998) paper in which, by comparing the cave art of Chauvet and Lascaux with the drawings of Nadia, a young autistic girl, he argues that the symbolic nature of language interferes with direct visual experience. For example, at certain moments during sculpting, my sense of self is aphasic. I do not mean that I have lost the capacity of language, rather language ability is not co-opted into my sense of self. We can understand this strange state of affairs by sidestepping the assumption that it is the self that determines the morphology of artistic activity and considering instead the view that it is the arc of activity itself that constructs a transient sense of self adapted to the task at hand (see also Malafouris (2008a, b) notion of tectonoetic awareness).

The clay-in-formation felt like it was both of the world and of me. The boundaries of my haptic self expanded to include the changing clay form and became indistinct, making it difficult to distinguish me from not-me. My eyes however lagged, still tending to see the clay as something beyond me. Hodder (2012) presents a view, originally formulated by Alois Riegl, that the history of art from ancient Egypt to late antiquity is characterised by a change in the primary mode of perception from haptic to visual. This view implies that the contemporary prohibition on touching art creates inflexible boundaries between people and art, leading to an impoverished experience.

Pink (2011) suggests that the five senses are not biological givens but constructs that define perceptual limits. If taken separately, each sense presents a different world view. She goes on to describe how alternative or amalgam senses might be constructed - a sense of freshness, for example. Likewise, Bäckström (see Fors et al. 2013) provides descriptions of multimodal perception in skateboarders. When sculpting, the senses of touch, movement and proprioception become effectively inseparable. Modalities and experience are blended and it becomes impossible to act uni-modally.

Hodder (2012) describes how, in Hegelian terms, a subject becomes aware of his/her existence by becoming aware of things that $\mathrm{s} / \mathrm{he}$ is not. It is the perception of things beyond the self that creates the sense of self. According to Bion (1967), the capacity to think co-evolves as the self separates from the world. Winnicott $(1953,1960)$ adds that the development of this thinking-self is provoked by the frustration of need. This is like Dewey's view, "Not without resistance from surroundings would the self become aware of itself" (Dewey 1934, p. 62).

For Thompson, the construction, maintenance and regeneration of boundaries (autopoiesis) is the hallmark of living things. "A physical autopoietic system, by virtue of its operational closure, gives rise to an individual or self in the form of a living body, an organism." (2004, p. 387) The sensational quality of the world is determined by the quality of these boundaries and the nature of the interactions that take place across them. The separation of organism from its environment in turn gives meaning to elements in that environment. Thompson uses bacteria as an example. The sensing capacity of bacteria transforms the molecule sucrose into food. In a positive cyclehaving a sensation reinforces the sense of self. Thompson equates this emerging quality of lived experience with the mind. 
Thompson's formulation (as with Barandiaran et al. 2009) implicitly assumes that the body and the mind share the same boundary. Not so for Dewey. "The epidermis is only the most superficial way of indicating where an organism ends and its environment begins...there are things outside that belong to it...that must be taken possession of if life is to continue... whether the pen of the writer or the anvil of the blacksmith." (1934, p. 61) Likewise, if we follow the logic of Clark and Chalmer's (1998) extended mind hypothesis, the self also becomes mutable, determined by the material culture that makes up the sensing mind at that moment - the swinging of an axe, the panning of a video camera or the pressure of clay against the palm. Malafouris refers to this continual un-ending reconfiguration and resampling of a plastic mind within a plastic culture as "Metaplasticity". (2015, p. 358).

Metaplasticity undermines any notion of a complete, finished mind or self. My contention is that the plasticity of clay helps to exposes the metaplasticity of the mindmaterial relationship in a way that is less accessible with other materials. When modelling clay, my sense of agency becomes inseparable from the changing form of the clay - the mental and the physical become blended. I watch, feel, smell and participate in an uncertain and unpredictable, physical process. When fully engaged in modelling I get a sense from the clay of the form it is about to take at the moment it takes it. It seems like the act of creation pushes the present into the future. It is like searching for an interesting pebble on the beach. Without a preconceived idea, I imagine the pebble only as I find it. In Hodder's complementary description, the pebble draws the human towards it:

"...the object pebble has been made a thing, it has been connected to humans by the process of gazing, noticing, recognising, comparing...It is the human that has been added to the pebble..." (2012, p. 24)

Derrida refers to a similar process when he talks of how the drawing hand overtakes the thinking head, the hand does not re-present an internal image, "it traces its own actions." (1993 p. 4).

While this is exciting, the level of uncertainly created by the unstable sense of self also provokes anxiety. The artist Markus Karstieß (unpublished interview, March 2015) refers to the need to accept this state of uncertainty and the unsettling sensation that accompanies it.

“... if you work into the open field it's like walking up...stairs and you think there is a fifth stair coming and there isn't and you step into this nothingness and this is the feeling that you have...this is what I think we should work towards when you want to succeed in creating a new artwork..."

Keats (1817) called the ability to withstand uncertainty "negative capability... being in uncertainties, mysteries, doubts, without any irritable reaching after fact and reason." Bion (1970), p. 125) subsequently used 'Negative Capability' in a psychoanalytic context to describe the capacity of the analyst, during a session, to tolerate the anxiety arising from not-knowing and to resist transference and counter-transference pressure to bring ambiguity to an end by introducing false certainties. Bion's understanding of 
'negative capability' serves as a good description of what it is like to tolerate the anxiety related to these emerging sculptures.

Karstieß (March 2015) talks about the discomfort viewers felt in front of his series of ceramic sculptures, "Fetishes" ;

“...people are very disturbed by the Fetishes and I think that it is because... they look at the sculpture and they have no idea of what that could be-it's not really a puppet, not really figurative, but it is a bit figurative, not really abstract... They don't know what it is but they know it has something to do... with themselves as being a human... so they are disturbed because they don't know..."

The visitors to the Substantia Inomminata (2014) exhibition were similarly disturbed by the indeterminate nature of the works. Somewhat anxiously, they explored each sculpture seeking a resemblance to something known. Almost all searched for a name for each sculpture and showed visible relief when they came up with one. Naming may play a dual task in the viewer's attempt to engage materially with these indeterminate works. Naming translates an uncomfortable expressive experience into a more manageable designative one (Malafouris 2013, p. 96). But naming may also be the linguistic expression of a process of enactive signification in which associative connections are made between an unfamiliar material sign (the sculpture) and more familiar, pre-existing concepts - a womb, dolphin, radiator etc. This is not to say that the sculpture came to represent a womb. Rather, there was a moment when a phenomenological feeling of "wombness" emerged from the beholder's engagement with a sculptural form which was neither a womb nor a symbol of one (Image 1). Malafouris refers to this process as "metaphoric projection" (2013, p. 102) and proposes it as a way in which conceptual possibilities can become substantiated. Significantly, there is no role for the imagination in metaphoric projection. It is a creative, physical/ mental act that happens, not in the head, but in the unfolding of the world.

\section{The Matrices series}

I want to explore further the mutable sense of agency and of self by describing the making of another series, The Matrices (2016). These sculptures were created by the repetitive addition of diagonally intersected cubes. This would normally create an everincreasing cuboid form but, in some places, an edge or a diagonal was made shorter than it should be, causing a deformation. I am interested in the nature of the disruptive agency that brings about this deformation.

Matrix 1 took the predictable form of a symmetrical cuboid structure during the first $12-16 \mathrm{~h}$ of work. Thereafter, while continuing to grow cube-by-cube, it started to become asymmetrical. (see Image 2) This deviation did not come as a surprise to me because I was intimately implicated in the action. And yet I had little sense of agency.

During the next $30 \mathrm{~h}$ of work, the sculpture took on an increasingly organic form despite its basic geometric structure (see Image 3). To make the cuboid subcomponents my hand/body/eye gestures needed to be exact and deliberate. In contrast to the

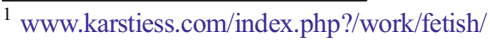




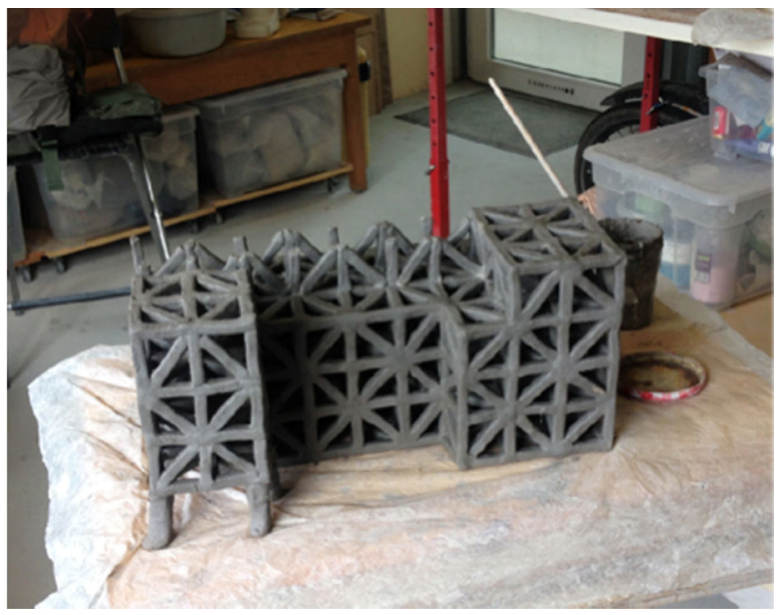

Image 2 Matrix 1, showing asymmetry

Substantia Inomminata series, making the Matrices was like working in slow motion. Smooth, sculpting gestures were replaced by a cube-by-cube freeze-frame advance. There was a stark contrast between these regular, precise and invariant gestures and the increasingly chaotic growth of the work-in-progress. Despite the chaos, there was rarely any doubt about where the next cube was to be placed. It was decided from within the hands-eye-clay-sculpture system. (See Image 4 for finished piece).

The dexterity of the cube-making gesture came from having repeated it hundreds of times during a previous project. Dow (2017) suggests that such continuous and expert bodily gestures contain an implicit awareness of self. There was certainly a mild sense of mastery that went with these gestures. Indeed, it was quite disconcerting to experience purposeful action in the absence of a sense of personal agency. Malafouris $(2014$, p. 151) refers to such paradoxical situations as "the sense or consciousness of making in the absence of telos (in the sense of a complete given)" I

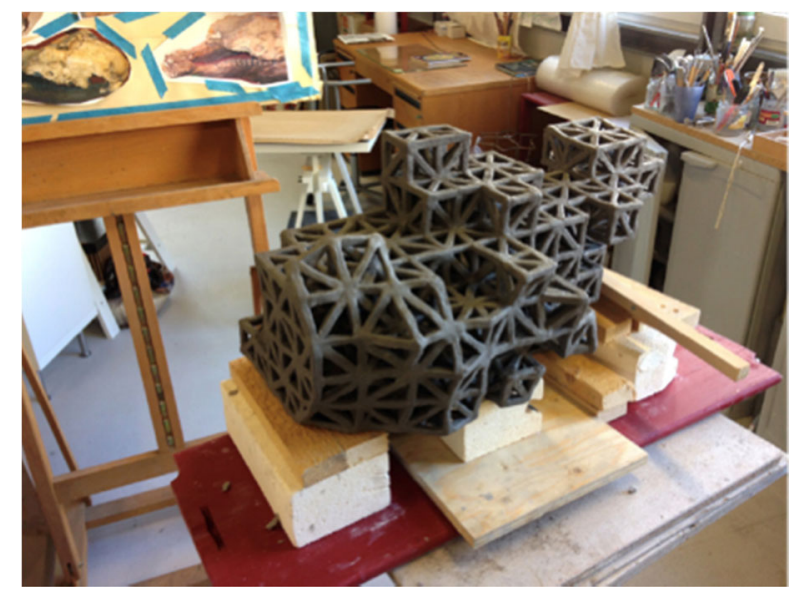

Image 3 Matrix 1, The beginnings of organic development 


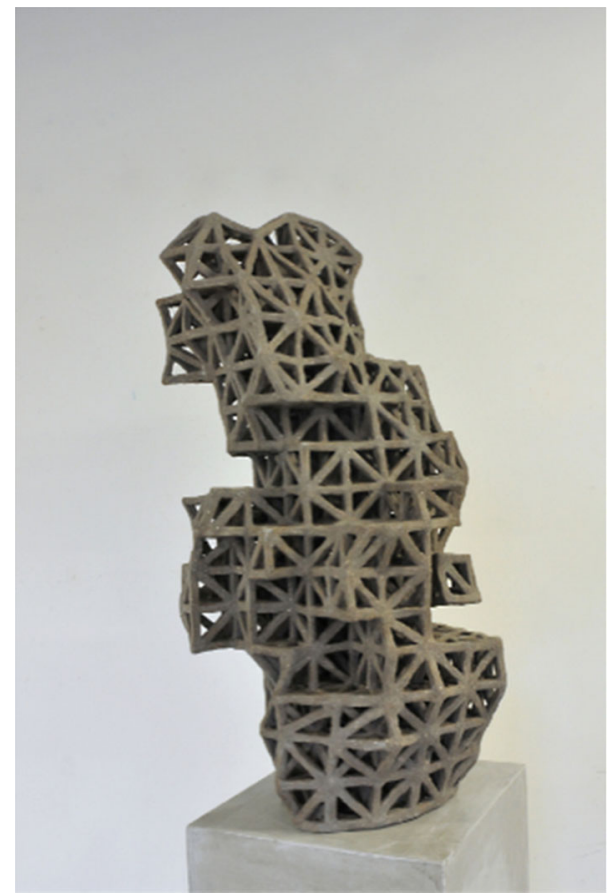

Image 4 Matrix $1(2016) 0.6 \times 0.25 \times 0.25 \mathrm{~m}$

felt a clear inclination to bring forth form from clay but I do not think it is accurate to describe it as $m y$ inclination. It was something I was a part of.

To be engaged purposefully in unintentional activity reminds me of Bateson's notion of "The Double Bind" - an injunction to comply with two contradictory commands (1973, pp. 142-9). Bateson positively connoted delusional madness as a creative response to the trap of a double bind. With the Matrices, the injunctions are imposed, not within the troubling confines of a disturbed family, but in the calm of an artist's studio. Nevertheless, the anxiety the injunctions provoked was real in terms of the perceived threat to the self. For Milner, painting was associated with similar emotional turmoil. "In one part of the mind, there really could be a fear of losing all sense of separating boundaries...in fact a fear of going mad" (1950, p. 16). I therefore think it is useful to consider these injunctions from Bateson's perspective. The sculptural substantiation of the crazy premise - to engage purposefully in unintentional activitymakes it conceivable. The clay ignores the fact that the two injunctions are linguistically inconsistent and illogical and goes on to take a physically coherent form anyway. There is certainly a tension in the sculptures between structure and indeterminacy (Substantia Inomminata series) and form and deformation (Matrices). But the tension is incorporated and stabilised in the making. The clay, working in concert with my hands, acquires an enactive sense of material agency that bypasses the simultaneous affirmation and denial of personal agency that is the lot of the linguistically formulated double bind.

Until now I have emphasised the anxiety associated with the dissolution of self and the uncertain sense of agency. But there is also an exhilarating feeling of integration 
with the materials around me. I am not referring to a transcendental or mystical experience here-quite the opposite. I do not leave the material world. I become integrated with it. Milner (1950 p. 142) describes a similar experience whilst painting:

“...there occurred, at least sometimes, a fusion into a never-before-known wholeness; not only were the object and oneself no longer felt to be separate, but neither were thought and sensation and feeling and action. All one's visual perceptions..., ideas about the object and action towards it, the movement of one's hand together with the feeling of delight in the 'thusness' of the thing, they all seemed fused into a wholeness of being which was different from anything else that had ever happened to me."

Bennett (2015) shows how art can provide a different perspective on the relationship between the self and the world. In her encounter with irreparably damaged artworks, she notes the hold that these "art-things" still have over her. Their damaged nature reveals something that Bennett says we normally overlook - the power of attributes that belong to the thing itself-colour, shape, texture, rhythm, temporality and materiality. Drawing on her concept of "vibrant matter" (2010) she argues that these broken things have a life-force which is independent of their human makers. Instead of supporting the view that art-works have human-like personalities, they emphasise that humans have thing-like properties. "The idea is not that things are enchanted with personality but that persons qua materialities themselves participate in impressive thing-like tendencies, capacities, and qualities." (p. 96). In these terms, the loss of sense of self might be reformulated as an increasing sensitisation to the thing-like qualities of the body and mind. Art-making as an expression of humanity is also a confrontation with the material nature of humans.

\section{In Pulverum Speramus and the pedocomparator}

As we have seen, the hylomorphic model suggests that an artwork is the physical realisation of an idea or 'visual mental representation'. I have described how, in my experience, art-making does not begin with an idea but is part of a tumbling, rolling hairball of impulses which gathers feelings, memories materials and disruptions to it. Most of the stuff that sticks is indecipherable in the abstract. The factors that may have precipitated art-making activity only become apparent in the course of the activity. I will illustrate this by describing the making of In Pulverum Speramus (2015, Image 5).

Here are some associations that became apparent during the making:

1) A push-puppet in the shape of a dog and/or possibly "Spotty Dog" - a puppet from the UK 1960's children's television series "The wooden Tops"

2) The memory of large, smooth, slate pebbles on beaches on the south coast of England - how each one is simultaneously an individual stone and one of a pile of stones.

3) Previous art-works assemblages. e.g. 


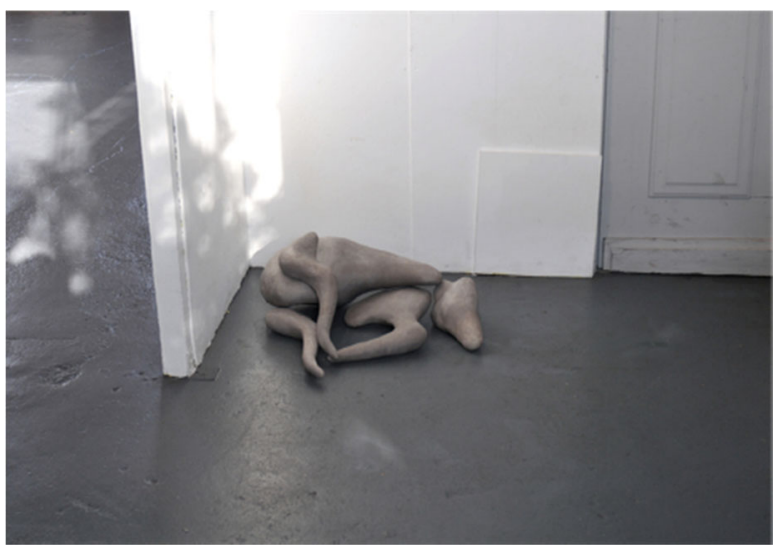

Image 5 In Pulvurum Speramus (2015) $0.35 \times 0.60 \times 0.45 \mathrm{~m}$

\section{Haploid, Diploid, Polyploid, Mongoloid (Everybody Talkin' 'bout Pop Musik) $(2010)^{2}$ \\ Jomon Spider Kit $(2013)^{3}$}

4) Life drawing classes during which, the act of drawing the model would paradoxically and disturbingly collapse the Gestalt of the whole body, creating the perception of the model as a series of body parts.

In the context of the above associations (which, as I have said, manifested themselves only later) I made some sketches. The goal was not to create an external reproduction of an internal visual image. If I already had an image I would not need to draw it. The function of sketching was exploratory-like the search for an interesting pebble or Derrida's drawing hand overtaking his thinking head.

In the next stage I made a clay maquette of each piece. The forms were partly defined by the sketching, but the transformation from $2 \mathrm{D}$ to $3 \mathrm{D}$ provided another opportunity for creative exploration. If I keep clay humid I can work indefinitely with it until the piece has found the shape it needs. This project was an assemblage of six, separate pieces but, once made, the pieces did not seem to fit well together-experienced as "did not like being together". As a result, I re-modelled several of them until they felt more comfortable in each other's company.

The final assembly is about five times the size of the maquette. Scaling up requires no dimensional transformation but does demand a change in definition. The maquette is like a 3D sketch. It is only as good as is necessary to expose the overall formal relationships, leaving the details and the juxtaposition of sub-parts unresolved. The final pieces are therefore not slavish reproductions but reactions to the experience of modelling the maquette.

There were two final transforms. Once assembled, I found that that, by removing one of the legs, the work became literally and figuratively more open. But while

\footnotetext{
${ }^{2}$ www.paul-march.com/artwork/3042788-Haploid-Diploid-Polyploid-Mongoloid-Everybody-Talkin-boutPop-Musik.html

${ }^{3}$ www.paul-march.com/artwork/3303823-jomon-spider-kit.html
} 
looking at the work with a fellow artist we agreed it remained too linear. After a few moments, my colleague bent down and moved the head from the front of the body to the back. With this simple gesture, the work came into its own. She had found the pebble for me.

I now want to show how Latour's description of the transformational powers of the pedocomparator may help us to understand the artistic process better. In "Pandora's Box", Latour (1999) shows how science proceeds by a series of consecutive transformations of matter into concept. He illustrates this by describing the nature and function of the pedocomparator - a tool for charting soil samples.

The pedocomparator is a flat case divided into a grid of cubic containers, each destined to hold a single soil sample. The samples are organised vertically in terms of depth of origin and horizontally in terms of geographical location. The transposition of soil from the ground to the relevant cube corresponds to a transformation of material to sign. The systematic arrangement of samples reveals gradations in colour and shade across the samples. The pedocomparator turns soil into a chart, creating meaning by defining the nature of the interaction between soil researcher and soil. This embodied act of charting helps the researcher choose where to search next.

The soil samples are subjected to further abstractive transformations. A standardised colour coding system (the Munsell code) converts the soil chart into serial numbers. Each number is linked to a location/depth coordinate which can be transposed onto a map of the original terrain. Through this series of transformations, the researcher arrives at a linguistic/numerical description and explanation of soil variation across an area. The emerging words do not resemble or represent the soil or the terrain. The discontinuous series of transformations causes the "transubstantiation" (Latour 1999, p. 64) of a thing to a sign.

By recording the pathway of transformations, it becomes possible to retrace and reproduce them. Scientific knowledge is thereby rendered credible. But Latour points out that, once scientific knowledge is established, it becomes detached from the pathways of its acquisition, thereby separating knowledge from the matter and activity of its making. Instead of remaining part of the world, knowledge ends up reflecting it. Latour concludes:

"We have taken science for a realist painting, imagining that it made an exact copy of the world. The sciences do something else entirely-paintings too, for that matter. Through successive stages they link us to an aligned, transformed, constructed world.” (1999, p. 79)

Latour's conclusion is consistent with artist Anslem Kiefer's view of the relationship between art and life.

"The artist always takes objects from... the world and transforms them. Once transformed they are no longer there. That is the relationship between life and art." (2016 interview with Laure Adler, 24.45-25.00).

Comparing Latour's description of the transformational powers of the pedocomparator with the making of In Pulverum Speramus highlights three common threads. First, both are defined by a series of clearly definable transformations characterised by the interplay of material and experiential progression. In neither case 
can the process of transformation be described as one of objectification. Second, successive transformations are not re-presentations of antecedent materialised concepts. Despite clear associations with the previous manifestations, each transformation is diffractive rather than reflective (Barad 2007). Third, both transformational pathways occur under certain constraints. In line with the generally accepted view that science proceeds within an explicitly operationalised framework, the pedocomparator directs and delimits the behaviour of the soil scientist. What may be more surprising is that, contrary to the popular, romantic view that art proceeds by rejecting prosaic modes of operation, these three case studies show that art-making too can be highly constrained, for example by the requirement to create structured indeterminacy, or to work purposefully in the absence of a specific directive, or to create an assembly of things that expresses and remains faithful to a theme that is only apparent as the theme becomes expressed.

But there are also two important differences between the pedocomparator and In Pulverum Speramus. Firstly, the pedocomparator facilitates a process of increasing abstraction and reduction through material transformation. The making of In Pulverum Speramus involves no abstraction, no reduction - only iterative re-materialisation of experience. Secondly, using the pedocomparator does not encourage the user to take a meta-cognitive or meta-emotive stance and his/her subjective experience has only an implicit presence. With In Pulverum Speramus the re-materialisation of experience is, by definition, subjective and meta-emotive.

In Dewey's (1934) view, a living organism finds harmony in the world through the rhythmical and predictable interplay of activity and environment. Disruption to harmony presents the organism with a creative possibility. We have seen a similar dynamic regarding Winnicott's $(1953,1960)$ views on the development of thinking. Malafouris (2014) describes how creative opportunities occur as the mismatch between expectation and experience increases. In Dewey's view these mismatches provoke an emotional and cognitive reaction focused on the restoration of harmony. Scientific endeavour thrives on the manufacture and resolution of such points of disruption. In order to find solutions, scientists concentrate on situations where the "tension between the matter of observation and of thought is marked" (p. 14). Artists, on the other hand, are interested, not in solutions, but in "the phase of experience in which union is achieved" (p. 14) Thus, according to Dewey, artists seek situations of tension and resistance for their own sake. Or perhaps we do it for the sake of creating opportunities for meta-cognitive /meta-emotive diffraction, both for ourselves and for the viewer.

It follows from this that a successful artwork invites the viewer to join and continue the entanglement of mind and matter. It orients the viewer forward in time not backwards. A fired clay sculpture loses the plasticity that gave it such dynamic creative potential in the hands of the artist. To continue working as art, it must find a way of creating a metaplastic relationship with the viewer. A finished artwork is at grave risk of being separated from its generative process. Removing art from the workshop and displaying it in a gallery (perhaps even on a pedestal!) is not conducive to the continuing process of enactive signification. Instead it encourages what Ingold calls a retrospective view (2014a) in which the sculpture is taken as a clue to the nature of the mind of the artist. I wrote this paper, in part, as a way of trying to avoid this. By becoming case studies, the ceramic lumps I describe undergo yet another transformation. This time, like the soil samples in the pedocomparator, the transformation is abstractive. 


\section{Conclusion}

Whilst sculpting it feels to me that agency and creativity are not personal attributes but emerge out of the act of sculpting. When I monitor my sense of agency closely I get a confused, conflicting picture, but the overall sense is one in which I am in a creative partnership with clay. This sense is consistent with the creative process proposed by MET but is at variance with the hylomorphic model. The experience of sculpting is a disturbing one because the boundaries of the world and myself become transient, unstable and incomplete. I suggest that disturbing emotions may be an inevitable part of a process of enactive signification - part of the pleasure and of the pain. Extending Malafouris' notion of meta-cognition, I suggest that the sensuous plasticity of clay invites me to take a meta-emotive position and that playing with clay has the potential to be used as a tool to investigate the emotional parameters of material engagement.

I have described how enactive signification is associated with an anterospective viewpoint. By attending to the emerging sense of agency I feel on the cusp of-almost tripping into - an unfolding future. There is more work to do here in relating this sense of being implicated in the creation of durée with Chemero's (2016) notion of sensory motor empathy (an implicit, synergistic motor and perceptual linking between things and people) and Malafouris' notion of "creative thinging'- "a species" capacity for inventiveness that is inseparable from the capacity to affect and be affected through movement and sensation from the phenomenal qualities of the materials that surrounds us." (2014, p. 144).

In particular, I think it is worth investigating the connection between creativity and surprise. As long as I remain within this "unfolding, future-durée" my expectations disappear to be replaced by materially-anchored predictions. By this I mean that the recognition of creative change becomes embedded within the act of creation itself and so is no longer experienced with surprise. Within this regime, the experience of surprise (even delightful surprise) becomes a sign that I have moved out of the creative flow in order to observe it. In practical terms this means that these days I stop sooner that I would have done in the past. I used to think that, by pushing things a little further, I would finish something. Now, if the clay and I are working well together we tend to have already stopped before I have thought of doing so.

Acknowledgements I am grateful to Frederic Vallee-Tourangeau and the two anonymous reviewers for their helpful comments on a previous draft.

Open Access This article is distributed under the terms of the Creative Commons Attribution 4.0 International License (http://creativecommons.org/licenses/by/4.0/), which permits unrestricted use, distribution, and reproduction in any medium, provided you give appropriate credit to the original author(s) and the source, provide a link to the Creative Commons license, and indicate if changes were made.

\section{References}

Adler, L. (2016). Interview with Anselm Kiefer. Hors-Champs, France Culture, 11.1.2016, https://www. franceculture.fr/emissions/hors-champs/anselm-kiefer-12. March, P. (quote trans).

Bandura, A. (2006). Toward a psychology of human agency. Perspectives on Psychological Science, 1(2), $164-180$.

Barad, K. (2007). Meeting the Universe Halfway: Quantum physics and the entanglement of matter and meaning. Durham: Duke University Press. 
Barandiaran, X. E., Di Paolo, X., \& Rohde, M. (2009). Defining agency: individuality, normativity, asymmetry, and spatio-temporality in action. Adaptive Behavior, 17(5), 367-386.

Bateson, G. (1973). Steps to an ecology of mind: Collected essays in anthropology, psychiatry, evolution and epistemology. London: Paladin.

Bennet, J. (2010). Vibrant matter: A political ecology of things. Durham: Duke University Press.

Bennett, J. (2015). Encounters with an art-thing. Evental Aesthetics, 3(3), 91-110.

Benveniste, E. (1971). Active and middle voice in the verb. In É. Benveniste (Ed.), Problems in general linguistics. Meek, M.E. (trans.). Coral Gables: University of Miami Press.

Bion, W. R. (1967). Second thoughts. London: William Heinemann Reprinted London: Karnac Books, 1984.

Bion, W. R. (1970). Attention and Interpretation. A scientific approach to insight in psycho-analysis and groups. London: Tavistock Reprinted London: Karnac Books, 1984.

Boden, M. A. (1994). What is creativity? In M. A. Boden (Ed.), Dimensions of creativity. Cambridge: MIT Press.

Boden, M. A. (2004). The creative mind: Myths and mechanisms (2nd ed.). London: Routledge.

Chemero, A. (2016). Sensorimotor empathy. Journal of Consciousness Studies, 23(5-6), 138-152.

Clark, A., \& Chalmers, D. J. (1998). The extended mind. Analysis, 58(1), 7-19.

Derrida, J. (1993). Memoirs of the blind: The self-portrait and other ruins. Chicago: Chicago University Press trans P.-A Brault \& M. Nass.

Dewey, J. (1934). Art as experience. London: Penguin.

Dow, J. M. (2017). Just doing what I do: on the awareness of fluent agency. Phenomenology and the Cognitive Sciences, 16(1), 155-177.

Fors, V., Bäckström, A., \& Pink, S. (2013). Multisensory emplaced learning: resituating situated learning in a moving world. Mind, Culture, and Activity, 20(2), 170-183.

Gallagher, S., \& Miyahara, K. (2012). Neo- pragmatism and enactive intentionality. In J. Schulkin (Ed.), Action, perception and the brain (pp. 117-146). Basingstoke: Palgrave- Macmillan.

Gell, A. (1998). Art and agency: An anthropological theory. Oxford: Clarendon Press.

Hirst, D. (2012). http://www.damienhirst.com/video/2012/thoughts-work-life (15-15:30).

Hodder, I. (2012). Entangled: An archaeology of the relationships between humans and things. Chichester: Wiley-Blackwell.

Hogan, S., \& Pink, S. (2010). Routes to interiorities: art therapy and knowing in anthropology. Visual Anthropology, 23, 158-174.

Humphrey, N. (1998). Cave art, autism, and the evolution of the human mind. Cambridge Archaeological Journal, 8(2), 165-191.

Ingold, T. (2010). The textility of making. Cambridge Journal of Economics, 34, 91-102.

Ingold, T. (2013). Making: Anthropology, archaeology, art and architecture. Abingdon: Routledge.

Ingold, T. (2014a). The creativity of undergoing. Pragmatics and Cognition, 22(1), 124-139.

Ingold, T. (2014b). That's enough about ethnography! HAU: Journal of Ethnographic Theory, 4(1), 383-395.

Keats, J. (1817). http://keats-poems.com/to-george-and-thomas-keats-hampstead-december-22-1817/.

Latour, B. (1996). On actor-network theory: a few clarifications. Soziale Welt, 47(4), 369-381 Retrieved from http://www.jstor.org/stable/40878163.

Latour, B. (1999). Pandora's hope. Essays on the reality of science studies. Cambridge: Harvard University Press.

Le Witt, S. (1967). Paragraphs on conceptual. Art Artforum, 5(10), 79-83.

Malafouris, L. (2007). Before and beyond representation: Towards an enactive conception of the Palaeolithic image. In C. Renfrew \& I. Morley (Eds.), Image and imagination: A global history of figurative representation (pp. 289-302). Oxford: Oxbow Books.

Malafouris, L. (2008a). At the Potter's wheel: An argument for material agency. In C. Knappett \& L. Malafouris (Eds.), Material agency: Towards a non-anthropocentric perspective (pp. 19-36). New York: Springer.

Malafouris, L. (2008b). Between brains, bodies and things: tectonoetic awareness and the extended self. Philosophical Transactions of the Royal Society B: Biological Sciences, 363(1499), 1993-2002.

Malafouris, L. (2011). Enactive discovery: The aesthetic of material engagement. In R. Manzotti (Ed.), Situated aesthetics: Art beyond the skin (pp. 123-141). Exeter: Imprint Academic.

Malafouris, L. (2013). How things shape the mind: A theory of material engagement. Cambridge: MIT Press.

Malafouris, L. (2014). Creative thinking: the feeling of and for clay. Pragmatics \& Cognition, 22(1), 140-158.

Malafouris, L. (2015). Metaplasticity and the primacy of material engagement. Time and Mind, 8(4), 351-371.

Malafouris, L. \& Koukouti, M. D. (2017). More than a body: A material engagement approach. In C. Meyer, J. Streeck \& J. Scott Jordan (pp. 289-301). Intercorporality: Emerging socialities in interaction. Published to Oxford Scholarship Online: August 2017.

March, P. (2015). Unpublished interview.

Milner, M. (1950). On not being able to paint. Madison: International Universities Press.

Palmer, S. E. (1999). Vision science: Photons to phenomenology. Cambridge: MIT. 
Pink, S. (2011). Multimodality, multisensoriality and ethnographic knowing: social semiotics and the phenomenology of perception. Qualitative Research, 11(3), 261-276.

Renfrew, A. C. (2003). Figuring it out: The parallel visions of artists and archaeologists. London: Thames and Hudson.

Sylvester, D. (1975). Interviews with Francis Bacon. London: Thames and Hudson.

Thompson, E. (2004). Life and mind: from autopoiesis to neurophenomenology. A tribute to Francisco Varela. Phenomenology and the Cognitive Sciences, 3(4), 381-398.

Winnicott, D. W. (1953). Transitional objects and transitional phenomena-a study of the first not-me possession. International Journal of Psychoanalysis, 34, 89-97.

Winnicott, D. W. (1960). The theory of the parent-infant relationship. International Journal of Psychoanalysis, 41, 585-595. 